\title{
The study of Causative Verbs application in English
}

\author{
Ahmatjan Tash, Changhua Liu \\ School of Foreign Languages, Xinjiang University of Finance and Economics, Urumqi, China
}

Keywords: Causative verbs, English statements, Syntactic structure

\begin{abstract}
English causative verbs share some obvious common features in word formation and sentence structure. In this paper, with the theory beginning of semantic field, classifies the verbs into several groups. Then, on the basis of lexical semantics, it gives a comparatively complete analysis on the ways of their lexical changes and syntactic formation with being given on the insinuated meanings of the present and past participles, which derive from the causative verbs.
\end{abstract}

\section{Introduction}

In the process of statements generated, the same kind of semantics, within a language, may be linked with a variety of language form. In different languages to express the semantic of language form, are more likely to present a different state [1]. These languages form show the specific grammatical structure, or the form of changes in word form, or characterized by a form of no mark of zero. From the perspective of language input and language recognition, the different language form, through semantic same linked to the inner link between, appear very important.

"B" (caused) as a semantic category, in the language has the characteristics of universality. This can be found in the real world is the basis of sex. Things change for some kind of behavior, or state, can is the result of their own role, can also is the result of external effect. In the latter case, something for some kind of behavior, change, or state, there are always another to the external force of things. Under the force of the external connection of two things, the relationship between performance on cognitive, is a semantic category "caused" [1]. In the same way, the "caused" the semantic characteristics in people looking for language forms to generate statements, mapping to the syntax, there were all kinds of specific performance, implementation for different forms of causative. And these forms are at different levels, and from the linguistic form to the semantic in the process of speech recognition performance for different cognitive value.

This paper focuses on causative verbs semantic characteristics, first carries on the classification, and then its lexical and syntactic structure to compare the depth, aims at contributing to the research of solid righteousness verb in English, as well as English grammar teaching to try something new.

\section{The causative verbs system}

The division of causative verbs system depends on the classification of human knowledge. Mood is held by the people of objective things and objects attitude and experience, such as happy and unhappy, sorrow and grief, excited and anger, fear and despair, appreciate and love [1]. All these happiness, anger, sorrow and joy, love, fear and hate, are people different attitude towards reality and unique form of experience.

Based on the theory of semantic field, a core concepts related with the same semantic features of several words can be combined together, form a field [1]. Each semantic field is a network of words (lexical network), or miniature semantic system, English causative verbs can be divided into three subsystems.

Enthusiasm causative verb. Positive is said a kind of relaxed and happy, at ease, narcissism, pride and even a sense of satisfaction of schadenfreude. Its core vocabulary to do, the rest are respectively satisfy, amuse, entertain, excite, move, inspire, encourage, touch, thrill, interest, charm, attract, fascinate, captivate, convince, dignify and assure, etc. 
Negativity causative verb. Negative including not happy, not satisfied, disappointed, sad, panic, anger, embarrassment, confusion, mistrust, not relaxed feeling, such as to annoy the central word, the rest is irritate, disgust, grieve, plague, harass, aggravate, trouble, disturb, distress, dismay, agitate, upset, worry, bother, beset, depress, puzzle, confuse.

Intermediate causative verb. Intermediate emotions mainly are curiosity, masturbation, plain and quiet. This kind of words at the center of the words is a surprise, followed by astonish, tackle, astound and amaze, stun, dumbfound, reflux and so on. Intermediate has positive and negative function, reflect a kind of attitude towards life.

\section{The causative sentence structure}

Causative forms first show the structure. This kind of structure is represented by the modern Chinese, can sign into:

$\mathbf{S}+$ Let $+\mathbf{O}+\mathbf{V}(\mathbf{p})$. In the language column, $\mathrm{S}$ is the subject of the sentence, $\mathrm{O}$ is "make" object, $\mathrm{V}$ (p) is the object complement, that is a verb phrase, (p) is the $\mathrm{V}$ p phrases can be the predicate $\mathrm{V}$ of polished rod, also can be the predicate verb phrase $\mathrm{V}$ p V with a variety of ingredients.

This kind of structure is forming in Chinese, English, German and French, which are the language of the typical performance [2]. Some call it as modern Chinese language, in the language and style, subject $\mathrm{S}$ state of the object $\mathrm{O}$, change, or some kind of behavior. The language and type of verb causative meaning are represented by the specific syntactic structure acts as causative form, namely "make, make, called," and so on.

If the causative semantic features such as former summarized as a kind of external force, then the causative semantics is generalized. Namely the semantics is not just to "make, make, called," this a few typical words to load, and in the modern Chinese grammar and language structure of the sentence before a verb, also carrying the generalized causative semantics. The verbs such as: "please, command, sent, ban, force," and so on, the semantic layer also contains "led, causative" the semantic elements.

$\mathbf{O}+\mathbf{C a u s e}+\mathbf{O}+\mathbf{V}(\mathbf{p})$. The grammatical structure became a causative meaning of causative form the first level: hierarchical structure. Characteristics as the grammatical features of language in word order, such as Chinese, English, structure level in language input or recognition at all levels is much simpler than later when it comes. Because it is perhaps the most conform to the nature of the human brain cognitive structure [2]. That's why we put a language form as the first level in the form of causative reasons.

Make/have+sb+do/done+sth. Make structure: make sb. Do /done STH. , basically see is active or passive. For example:

He top service his son read every night.

The boy shouted to make himself heard.

She made the house cleaned.

However, if make is passive, structure: sb. be made to do. For example: His son was made to read by question very night.

The use of the causative verbs "have":

1) Have + object + the past participle

This structure there are generally two kinds of meaning, one is left, secondly, passive. The former expresses the subject will cause something happen or be done, the latter has nothing to do with subjective will completely.

2) Have + object + the present participle

This structure has two meanings: one is to enable sb. to do STH. , another is with a laparoscope, usually connected to a negative word, said forbid sb to do STH.

\section{The use of causative sentence structure}

Causative verbs word-formation ability strong, a lot of words through the derived method (derivation) into nouns, adjectives, such as satisfy - satisfactory. Another way of morphological 
transformation is through the flexor twists (inflection) add - ing or -ed in constructive causative verbs in the present participle and the past participle, such as fascinating, fascinated. From the semantic analysis of causative verbs participle form is of great significance.

Nominalization. Causative verbs in plus noun suffix into nouns, such as: astonishment, amusement, who, satisfaction, mortification, fascination, confusion, 'annoyance, disturbance and so on [3]. Some verbs by parts of speech conversion (conversion) directly into a noun, or they can be a noun and can be used as a verb, such as surprise, interest, worry, delight, alarm, puzzle, regret and so on.

Has evolved by sexual causative verbs nouns, in front of it plus prepositions to and possessive pronoun or noun possessive, way adverb phrase, said some things of nature, status, or the results of specific actions make the person produces a reaction, nominalization after still have causative verbs. For example, amazement/annoyance/who/regret/satisfaction/delight was passed.

Adjectives. Causative verbs into there are two ways to describe the part of speech, is a kind of verb and adjective suffix derived into common adjectives, such as: DE - rightful, pleasant, painful, tiresome, troublesome, awful, etc [3]. The other is a plus inflectional ending - ing and - Ed constitutes a present participle and the past participle.

Adjectives modify nouns refer to more content, less people. This kind of words can be reduction in dynamic structure: Shocking rumours be equal to rumours shock someone. Tire some work be equal to work tires someone. Painful experience be equal to experience have someone. In addition to the objective situation make the person produces, specific meaning people will trigger other people's feelings, such as disgusting smugglers, terrifying murderers, charming ladies, etc [3]. We can say a frightened bird, confused a stranger, an annoyed the customer, but can't say a frightened story (should say a frightening stories), a confused result (said should be a confusing result). But sometimes they can modify the personification of, can have the feeling ability, such as the troubled face, its ehrs determined expressions using, the angry Sea, the melancholy moon, etc.

Ordinary adjective suffix as - ful is much more emotional adjectives, such as shameful, frightful, delightful, can stir up emotions and said some adjectives can be said to feel emotions such as fearful, cheerful, curious, and so on. According to sexual causative participle form of the verbs, it is very easy to distinguish between these two classes of words, the present participle said more emotional, and the past participle said feel emotions. The following on it (representative) and him (representative) as an example:

It is amusing $\rightarrow$ He is amused.

Embarrassing $\rightarrow$ embarrassed.

Fascinating $\rightarrow$ fascinated.

Startling $\rightarrow$ startled.

Inspiring $\rightarrow$ inspired.

Bewildering $\rightarrow$ bewildered.

Exciting $\rightarrow$ excited.

Confusing $\rightarrow$ confused.

Disappointing $\rightarrow$ disappointed.

Adverbs. Causative verbs in the present participle and the past participle are stuffily into adverbs. Such a personality causative verbs to derive the two adverbs, they still reflected in the differences in semantic provoke emotions and feel the distinction of the two [4]. Excited mood adverbs object for the behavior and state verb, and modify some sensory verbs main feel mood adverbs. For example,

He speaks amusingly $\rightarrow$ I listen amusedly.

She laughs charmingly $\rightarrow$ I admire her charmed.

The flowers bloom delightfully $\rightarrow$ I look at them delightedly.

He behaves disgustingly $\rightarrow$ I left disgustedly.

The game goes on excitingly $\rightarrow$ I watch excitedly. 


\section{The syntactic changes of causative verbs}

Syntactic change points to in under the condition of no change of word meaning, through the words form change and transformation of syntactic structure to implement the synonymous words [4]. Sexual causative verbs syntactic changes involving the voice initiative (activization) and passive (passivation) and its present participle forms.

The initiative. To facilitate the descriptive causative dynamic behavior of the process, gradually and the cause of action, state, and behavior is called agency (agent), the behavior of the object (generally refers to a person) as the dative case (recipient). In the active voice, their relation can be expressed as: / + make verb + patient person [4]. The following selects several typical words to explain the relationship between the parts of the sentence:

The football game fascinated the spectators.

The magazine disgusted the artist.

The dirty words embarrassed the lady.

His behaviour surprised us.

The tiger frightened the domesticators.

The news of the victory encouraged everybody.

The boy. s answer satisfied the teacher.

The cartoon amused the children.

Passive localization. For passive localization of causative verbs from active transition, the dative case is a subject, and corresponding prepositions and illocutionary constitute the adverbial. Signs of prepositions as the illocutionary except for use by also may be at or with [5]. By generally represent the direct cause of, and with some is indirect. Sometimes by/at/with the usage of the caused overlap, that is difficult to say which is right, with traditional prescriptive method which is wrong. It is best to descriptive method, listed some possible. For example,

The spectators were fascinated at the football game.

The artists were disgusted a/with/by the magazine.

The lady was embarrassed at/by the dirty words.

We were surprised at his behavior.

The domesticators were frightened by the tiger.

Everybody was encouraged by the news of the victory.

The teacher was satisfied with the boy. s answer.

The children were amused by the cartoon.

The past participle form of causative verbs infinitive often said after the causes of some, in the words of man:

I was confused to learn of his latest decision.

She was exasperated to find nobody at home.

The passengers were irritated to be kept waiting so long.

The present participle is changed. Causative verbs in the present participle as predicative in the sentence, the subject is illocutionary, prepositions to plus the dative case as adverbial [5]. After change the syntax structure, the present participle can be reduced to the corresponding sex causative verbs. For example,

The football game was fascinating to the spectators.

The magazine was disgusting to the artist.

The dirty words were embarrassing to the lady.

His behavior was surprising to us.

The tiger was frightening to the domesticators.

The news of the victory was encouraging to everybody.

The boys answer was satisfying to the teacher.

The cartoon was amusing to the children.

Causative verbs is simply the vast English notional verbs in a small group, and traditional grammar can't there is no need for this type of verb for intensive analysis. Communicative grammar is a descriptive grammar in fashion now [5]. This syntax has broken the traditional lexical and syntactic 
boundaries, centering on the ideological concept, with communication purposes, a bit stressed can express the same idea in different language forms.

\section{Conclusion}

The study of the causative verbs in vocabulary teaching and grammar teaching has important practical significance. Students sometimes is hard to single by grammatical functions that find out the difference between the present participle and the past participle. This article, starting from the theory of semantic field to the causative verbs. And based on lexical semantics, a comprehensive analysis of the morphological variations and syntactic structures, and emphatically expounds the use of causative structure.

\section{Acknowledgements}

This research was supported with a research grant: 2016BS015; 2016JG0209 from Xinjiang University of Finance and Economics .

\section{References}

[1] G. L. Li, Causative structure research, Journal of Zhengzhou normal university, 2011, vol. 1, pp. 24-27.

[2] T. M. Liu, Have the semantic constraints of the causative structure and its acquisition, Journal of PLA foreign languages institute, 2006, vol. 3, pp. 32-36.

[3] L. Sh. Jiang, Grasp modern Chinese, Beijing: the commercial press, 2013, vol. 2, pp. 18-23.

[4] X. M. You, The choice of the finite verb English theory, Foreign language teaching and research, 2008, vol. 10, pp. 23-27.

[5] M. Y. Wang, The structure of the Silk Road economic belt and the strategic significance, Journal of Tianshui administration institute, 2013, vol. 6, pp. 43-46.

[6] T. W. Huang, Collins COBUILD English grammar, Shanghai: Shanghai foreign language education press, 2014, vol. 2, pp. 52-56. 